\title{
Negotiating Content with Learners Using Technology Enhanced Teaching and Learning Solutions
}

\section{Megan Hastie*}

Brisbane School of Distance Education, Queensland, Australia Hear and Say WorldWide, Brisbane, Queensland, Australia

E-mail: megan@hearandsaycentre.com.au

\section{Nian-Shing Chen*}

Department of Information Management

National Sun Yat-Sen University

No. 70, Lien-Hai Rd., Kaohsiung, 80424, Taiwan

E-mail: nschen@mis.nsysu.edu.tw

\section{Richard Smith}

School of Education

Southern Cross University

Coffs Harbour, NSW, Australia

E-mail: smith.richard211@gmail.com

*Corresponding author

\begin{abstract}
This paper examines issues around learning 'content' and its place in the new digital learning culture. We focus on the increasing demands of digital learners for content that is relevant and the challenges this poses if educators are to stay relevant to them. We say 'relevance' is best achieved when content is negotiated with learners in collaboration with instructors. We describe strategies in which technology enhanced teaching and learning solutions have enabled learners to negotiate and create digitised learning content that is educationally, culturally and socially relevant. We cite two case studies that exemplify this approach: a trial of negotiated content with primary school aged digital learners at Brisbane School of Distance Education (BSDE), Australia, and the content decision-making processes used for the development of elearning courses for hearing health professionals and Auditory-Verbal Therapy at Hear and Say WorldWide Brisbane, Australia. We focus on the changing demands and skill sets of digital learners, their learning managers and subject matter experts, and the use of technology enhanced teaching and learning solutions as the negotiating tool in the development of digital content that is academically rigorous and also learner friendly.
\end{abstract}

Keywords: Negotiating Content; Digital Learners; Digital Content; Synchronous Cyber Classroom; Cyber Face to Face

Biographical notes: Megan Hastie is the Hear and Say WorldWide e-Learning Manager and an Education Queensland Senior Teacher, currently on secondment from Brisbane School of Distance Education. Her background is in early childhood education, e-learning, e-health and teacher professional 


\begin{abstract}
development programs, in diverse settings including rural-remote and Indigenous communities. In 1996 Megan presented research at Yale University School of Medicine on the use of the Internet for clinical problem solving by medical personnel. In 2006 Megan won a National Excellence in Teaching Award (NEiTA) - Community Merit. Her research has focussed on synchronous online teaching and learning via the Internet, the 'Blended Cyber' mode of delivery, instructional design for 'best practice' in the synchronous cyber classroom, decision-making around 'content' in the Digital Age, plus whole-of-community development projects using technology enhanced teaching and learning in Australia and in developing nations world-wide.
\end{abstract}

Nian-Shing Chen is a Distinguished Professor at the Department of Information Management in the National Sun Yat-sen University, Taiwan. He has published over 330 papers in the international referred journals, conferences and book chapters. He is the author of three books with one textbook entitled "e-Learning Theory \& Practice". Prof. Chen received the distinguished research award from the National Science Council, Taiwan in 2008. His current research interests include assessing e-Learning course performance; online synchronous teaching \& learning; mobile \& ubiquitous learning; Natural user interface \& Game-based learning. Professor Chen is a member of IEEE, ACM and the Chair for Expert Seminars and Web-based Tutorials, the IEEE Technical Committee on Learning Technology (http://lttf.ieee.org/). He is a Co-EditorsIn-Chief of the SSCI indexed Journal of Educational Technology \& Society.

Richard Smith is Emeritus Professor and part-time Professor of Education at Southern Cross University Australia. He also chairs the Board of Directors at the Australian Institute of Music Sydney. Richard has had a distinguished career in teacher education and education management. His most recent books with David Lynch are 'The Rise of the Learning Manager: Changing Teacher Education', 'Rethinking Teacher Education and 'Designing the Classroom Curriculum in the Knowledge Age'.

\title{
1. Introduction
}

The digital age has transformed teaching and learning in a way not seen before. The digital technologies have created a social computing and social networking phenomenon - a phenomenon whose birthplace was outside formal educational institutions. In a report to the European Union (2009), Ala-Mutka et al. stated that 'The boundaries between school and home, between formal, non formal and informal learning, between instructors and learners, between education and entertainment media, between content management systems, learning management systems and Web2.0 tools are blurring.' They go on to say that 'the emergence of blended learning settings can be read as a sign that the Learning 2.0 phenomenon may disrupt the very notion of the role of education and training institutions in contemporary society, setting the stage for a new schooling culture.' Leaving aside the inherent contradiction here between a disrupted education system and 'schooling', commentary like this leaves little doubt that we are in the midst of major change, change that is technology-driven, and change whose impact has the potential to redefine the very notion of what is learned and how it is learned. The technologies generate hard questions about what students at all levels should learn, how and where they learn and the relationships between mandated curricula and syllabuses and student choice. These matters and the new digital tools are a potent mix with endless possibilities for exploration by students. The fundamental challenges for teachers and 
education policy-makers lie in ensuring that what is taught and what is learned is relevant to both society and learners. At the centre of this debate is content itself and the role teachers play in determining its relevance.

In this paper we ask 'what is relevant content' and explore ways technology enhanced teaching and learning solutions can be applied to content development decision-making, to ensure content is equally academically rigorous and learner friendly. Traditionally content is the 'what' of teaching. It is what educators and governments expect learners to learn, and is traditionally what learners have been expected to know at the end of the learning process. It is also what learners expect to consume and, in most traditional educational environments, the conditioning for this begins at a very early age. In school systems, it is normally the case that content is shackled to government-driven curriculum policy decisions. In post school settings, content is determined by institutional purposes, vocational demands, and professional registration and accreditation requirements. Teachers have enormous freedom to create teaching strategies aimed at reaching the desired learning outcomes in students. Nevertheless, running parallel to these formal structures and processes, what counts as 'content' is moving and changing with every mouse click as Internet savvy users determine their own criteria of relevance. We explore these complex questions as we describe a process in which we have 'negotiated' content with learners, learning managers and subject matter experts in diverse settings using technology enhanced teaching and learning solutions to stay relevant to today's digital learners.

The literature makes emphatic declarations about the Web 2.0 era and its progeny of digital learners, and in particular, about their relationships with content. Siemens (2004) states that it is not enough to just know-how and know-what. He says these basic ways of knowing must now be supplemented with know-where, that is, the understanding of where to find the knowledge that is needed. Prensky (2001) continually reminds us that today's learners, the digital natives or Net Generation (Net Gen), are digital, connected, experiential and social, having grown up in a wired and wireless world. Coupled with generational propensities about immediacy, they want it 'now' and they know where to find 'it'. They don't wait to be shown - they browse and 'Tweet' and 'Google' it. They use adjectives such as engagement, interaction, visual, and active, when asked to describe their best learning experiences. Working in teams comes naturally to digital learners and peer-to-peer is a common learning arrangement, not just a way of sharing files (Prensky, 2001). Learning of this kind is informal and outside formal training programs (Conner, 2009). Moreover, Fanton (2009) identifies a new kind of literacy that is building and breeding outside schoolhouse walls:

Today's digital youth are in the process of creating a new kind of literacy; this evolving skill extends beyond the traditions of reading and writing into a community of expression and problem-solving that not only is changing their world but ours, too. In this new media age, the ability to negotiate and evaluate information online, to recognize manipulation and propaganda and to assimilate ethical values is becoming as basic to education as reading and writing. '

All this can be attributed to the Web 2.0 phenomenon which Musser and O'Reilly (2006) define as the set of economic, social and technology trends that collectively form the basis for the next generation of the Internet - a generation characterized by user participation, openness, and network effects. Samuel (2007) examines organizations that have been all about the message, and have for decades operated from a paradigm of message control and careful rollout. He says such organizations need to make the shift from message delivery to conversation and seeing members as content contributors. We 
argue that the same concept should be applied in education to elicit contributions from learners to engage them in content decision-making.

Knowing-where to find information and demanding and creating new ways of learning based on information technology defines today's digital learners according to the literature. This means learners are no longer willing to be passive consumers of content. Rather, they are willing and able to be content contributors with new tools at their fingertips and social media that enable them to converse, participate and network. Doing things in new ways means there is a new emphasis on learners interacting with information. This in turn shifts the emphasis from simply knowing 'what' to knowing 'what', 'how' and 'where'. It means that instructors need to focus on students doing more of the 'work' of learning rather than being passive recipients. A more active pedagogy concerned with learning management rather than instructor-centred control allows learners to work collaboratively with their instructors and fellow participants to negotiate and create content in a host of modes and ways (Chen, Wei, Wu, \& Uden, 2009; Chen, Kinshuk, Wei, \& Liu, 2011). Furthermore, it fosters practical applications and negotiated content decision-making with a range of stakeholders so that learning is networked and collaborative (Nowotny, Scott, \& Gibbons, 2003). This is quite different from decision-making around content development controlled by publishers and instructors, and taught without application.

With these issues in mind, we describe two Case Studies in which we demonstrate the use of technology enhanced teaching and learning solutions as the negotiating tool in content development decision-making in Australian educational settings which are being considered for wider application in developing nations in the Asia-Pacific region and beyond.

\section{Methodology}

In this paper we developed a new approach whereby learners, instructors and subject matter experts worked together in teams to use technology enhanced teaching and learning solutions as the negotiating 'tool' in content development decision-making. A state-of-the-art Learning Management System the Collaborative Cyber Community (3C) platform was used in both Case Studies to develop this new approach, through partnerships between the National Sun Yat-Sen University (NSYSU), Taiwan, Brisbane School of Distance Education and the Hear and Say Centre Brisbane, Australia. The asynchronous and synchronous features of $3 \mathrm{C}$ were applied to the development of elearning courses for the storage of course materials and to provide access to a synchronous cyber classroom using HomeMeeting JoinNet software.

Table 1. Holistic Blended Cyber Model

\begin{tabular}{|l|l|l|}
\hline 1 & PA + PS & Physical Asynchronous + Physical Synchronous \\
\hline 2 & PA + CA & Physical Asynchronous + Cyber Asynchronous \\
\hline 3 & PA + CS & Physical Asynchronous + Cyber Synchronous \\
\hline 4 & PS + CA & Physical Synchronous + Cyber Asynchronous \\
\hline 5 & PS + CS & Physical Synchronous + Cyber Synchronous \\
\hline 6 & CA + CS & Cyber Asynchronous + Cyber Synchronous \\
\hline 7 & PA + PS + CA & Physical Asynchronous + Physical Synchronous + Cyber Asynchronous \\
\hline 8 & PA + CA + CS & Physical Asynchronous + Cyber Asynchronous + Cyber Synchronous \\
\hline 9 & PS + CA + CS & Physical Synchronous + Cyber Asynchronous + Cyber Synchronous \\
\hline 10 & PA + PS + CA + CS & $\begin{array}{l}\text { Physical Asynchronous + Physical Synchronous + Cyber Asynchronous + Cyber } \\
\text { Synchronous }\end{array}$ \\
\hline
\end{tabular}


We designed a three-step model that exemplifies a shift from traditional content delivery in a 'Physical Face-to-Face' (PF2F) mode of delivery to the 'Blended Cyber' (BC) mode of delivery as used in our study. There are ten possible interpretations or options that can be defined as 'Blended Cyber', as illustrated in Table 1.

The Blended Cyber mode can lead eventually to a third fully 'cyber' mode of delivery, the 'Cyber Face-to-Face' (CF2F). The shift from Physical Face-to-Face to Blended Cyber to Cyber Face-to-Face mode is illustrated in Figure 1.

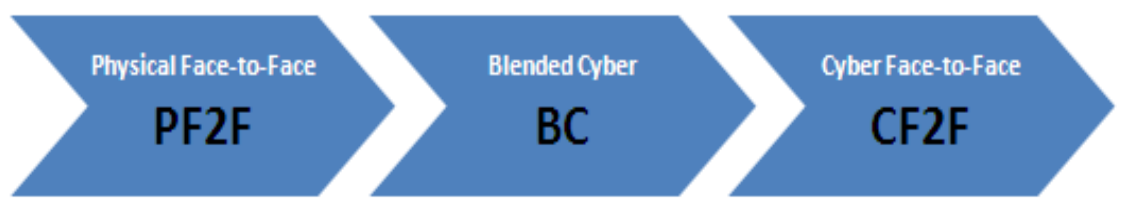

Figure 1. Our three-step model exemplifying the shift from PF2F to BC to CF2F mode

In the Physical Face-to-Face (PF2F) mode the content is delivered onsite with all participants physically present and face-to-face. In the Blended Cyber (BC) mode it is possible for participants to operate in a variety of ways: they may be physically face-toface $(\mathrm{PF} 2 \mathrm{~F})$ and access the Cyber Asynchronous resources (PF2F $+\mathrm{CA})$. They may also be physically face-to-face and access their instructor and fellow participants who are physically face-to-face (PF2F) using Cyber Synchronous technologies (PF2F + CS). Another variation for Blended Cyber participants is to link with a Physical Face-to-Face (PF2F) environment and to access Cyber Asynchronous resources (CA) using a blend of Cyber Asynchronous and Cyber Synchronous modes (PF2F + CA + CS). The third mode of delivery, the Cyber Face-to-Face (CF2F) mode is fully cyber with all content delivered to participants who are offsite and linked to the instructor and fellow participants using synchronous technologies for scheduled synchronous sessions.

We applied Gagné's instructional design theory (Gagné, et al 2004) to the development of our approach and adapted this for technology enhanced teaching and learning to inform our decision-making around content (Hastie, Chen, \& Kuo, 2007). We used Gagné's nine instructional events and their corresponding cognitive processes to create a framework to focus on outcomes. We applied these instructional events to develop a sequence for our teaching and learning, to:

(1) gain attention (reception)

(2) inform learners of the objective (expectancy)

(3) stimulate recall of prior learning (retrieval)

(4) present the stimulus (selective perception)

(5) provide learning guidance (semantic encoding)

(6) elicit performance (responding)

(7) provide feedback (reinforcement)

(8) assess performance (retrieval)

(9) enhance retention and transfer (generalization).

In this paper we focus on how educational providers can adapt traditional Physical Face-to-Face (PF2F) programs to a Blended Cyber (BC) model of delivery. Thus, we define 'Blended Cyber' as 'the use of a combination of different instructional methods, different modalities and delivery media, including online and Face-to-Face Instruction with participants physically present and/or 'cyber' (Chen et al., 2005). 


\section{Two Case Studies}

Based on the main theme of user generated content in Web 2.0 applications, we proposed a new concept of learner negotiated content for online learning in two authentic case studies. Case Study 1 describes simple strategies used to negotiate content with students aged 5 to 10 years using Web 2.0 technologies in the synchronous cyber classroom. Case Study 2 describes the reports on a new collaboration that commenced in 2009 between the Hear and Say Centre (Hear and Say), Brisbane, Australia, Brisbane School of Distance Education (BSDE), Australia, and the National Sun Yat-Sen University (NSYSU), Taiwan, in which Web 2.0 technologies enabled the development of course content for tertiary level learners and a subsequent shift to a Blended Cyber mode of delivery.

Case Study 1 reports on a trial of online synchronous teaching and learning by Ms Megan Hastie of Brisbane School of Distance Education (BSDE), Australia, and Professor Nian-Shing Chen of the National Sun Yat-Sen University (NSYSU), Taiwan undertaken over a period of six years (2004-2010). A range of age-appropriate strategies were used to negotiate content with students aged 5 to 10 years using technology enhanced teaching and learning. Research findings from the trial suggest that this approach resulted in enhanced cognitive functioning in learners from early childhood to tertiary level and that a significant factor in the achievement of these outcomes was the application of best practice in instructional design in the synchronous cyber classroom (Levy, Wang, \& Chen, 2009; Wang \& Chen, 2009; Wang, Chen, \& Levy, 2010a; Wang, Chen, \& Levy, 2010b). A particular focus of the collaboration was the use of technology enhanced teaching and learning strategies to bridge the digital divide in Australia and the Asia-Pacific region (Chen \& Ko, 2010; Hastie, Chen, \& Leeming, 2009; Hastie \& Chen, 2006, 2008).

As part of this collaboration with NSYSU, a negotiated content approach had been used with primary students aged 3 to 10 years of age at BSDE. The students enrolled at BSDE for a range of reasons and all were geographically, educationally and socially isolated. A variety of distanced education programs and resources had been developed over many years to help the students and their teachers overcome the 'tyranny of distance'. With the advent of Web 2.0 digital tools, fledgling cyber synchronous technologies such as Netmeeting were used to augment the school's traditional correspondence mode of delivery. The collaboration with NSYSU which commenced in 2004 and provided access to the Collaborative Cyber Community (3C) platform, a Synchronous Learning Management System (SLMS), and the cyber synchronous classroom (JoinNet) with its full suite of cyber synchronous tools. The negotiated content approach was identified as worthy of further investigation by the teacher through observations of learners and learning. It was noted that young learners do best when they are actively engaged in learning about topics that are of personal interest and relevance to them and that this results in them developing skills and attitudes that are deeper, richer and more enduring. The teacher used the 3C platform, and the cyber synchronous classroom feature to create a virtual 'space' in which she could interact with and work with her students - students with whom she would otherwise have little contact and minimal opportunity to provide direct instruction.. Participants were able to use the synchronous interactive whiteboard, Voice over Internet Protocol (VoIP), chat room and webcam during live sessions. When used in conjunction with the negotiated content approach, the Web 2.0 tools in the 3C synchronous cyber classroom enabled the teacher and learners to create digitised learning content that was educationally, culturally and socially relevant to them as they worked collaboratively in CF2F mode (Hastie, Chen, \& 
Todd, 2008). The lesson objectives were explicitly stated and accepted by participants at the start of each CF2F session, as shown in Figures 2 and 3 below:

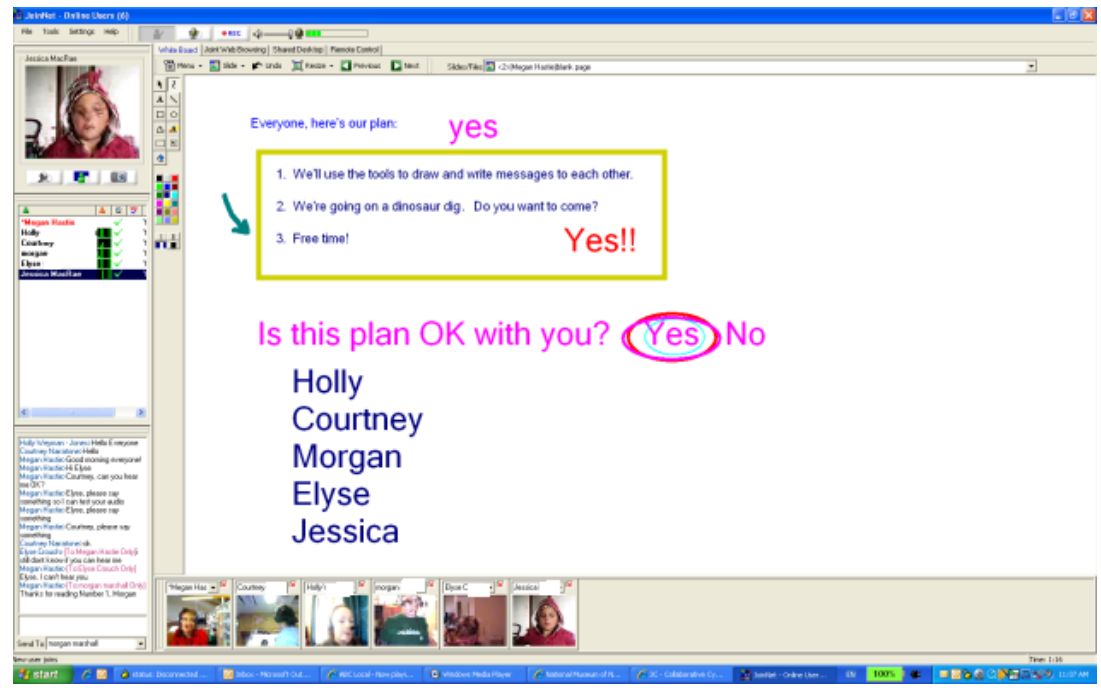

Figure 2. A screen-capture showing an example of the negotiated content approach using the Web 2.0 tools in the $3 \mathrm{C}$ synchronous cyber classroom

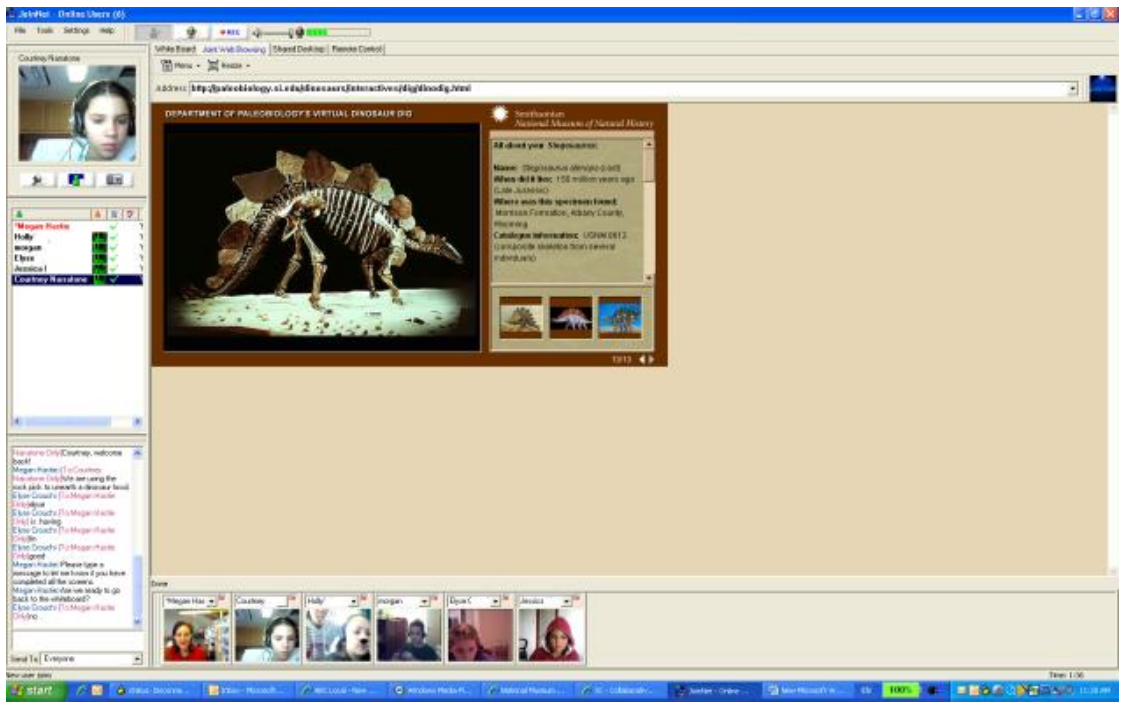

Figure 3. An example of students working on a virtual 'dinosaur dig' in the 3C synchronous cyber classroom

The teacher devised a novel approach to use with students during online sessions in the synchronous cyber classroom called 'Explorers Club'. She invited the students to join with her in exploring topics of interest. This approach was discussed with school administrators, the students' parents and the students themselves. In the first online session for each term, the teacher asked the students to 'brainstorm' ideas for lesson content. This was negotiated online in the synchronous cyber classroom between individual students, small groups of students and the teacher. At the end of each online 
session the teacher invited the students to plan topics collaboratively for the next session, thereby developing a cyclical planning process in which each lesson was linked to the next and through which students were engaged in ongoing research and planning.

Throughout the trial the teacher applied an instructional design model (Gagné) that sought to gain the students' attention, inform them of the session objectives by providing an 'advance organizer' (that is, the plan that had been developed by the students and their teacher for the session), and help them recall their prior learning. The teacher presented the stimulus and encouraged the students to respond by encoding information on the interactive synchronous whiteboard, through verbal interaction via VoIP, and through feedback in the chat room. In this way the teacher and classmates provided feedback to each other in a process of participatory collaborative teaching and learning. The teacher was able to assess student performance throughout the session through direct observation and interaction with the students. The teacher was also able to review the student's learning outcomes by viewing the recording of the session afterwards. At the end of each session the students were involved in creating the content for the next session. This resulted in a cyclical planning and content creation process that was designed to enhance the students' retention and transfer of their new learning and knowledge to their academic studies and everyday lives.

Typically the students in the early childhood age group (5 to 8 years of age) selected and negotiated content that matched their developmental needs and skills. Predominantly the topics they chose related to their growing understanding of the natural world (Science and Studies of Society and Environment). Their literacy skills developed in tandem with their knowledge of specific content through their use of digital 'tools' to encode their information and participate in the development of shared content. Older students aged ( 9 and 10 years) were able to work collaboratively in groups to select, create and negotiate content of broader scope and depth. For instance, the students chose 'Endangered Species' as a broad topic and then they each selected an endangered animal for individual research. In subsequent online sessions the students presented their research by encoding their findings on the interactive synchronous whiteboard and by interacting with their classmates' contributions. This process enabled the sharing of new information and knowledge amongst the group and furthermore, it enabled the sharing of the teaching role. The students were able to name the sources of their research and the reasons for accessing specific resources. The students accessed digital resources such as Google, Google Images, Wikipedia, Kid Cyber, Enchanted Learning, Ask.com, and Answers.com. The topic, 'Endangered Species', which the students chose first, lead them to a related topic 'Extinct Animals'. By linking 'Endangered Species' with 'Extinct Animals' the students demonstrated their ability to not only create their own content, but also take control of the sequencing of their learning and make deliberate (and observable) meta-cognition decisions, that is, to engage in cognitive scaffolding. Guest speakers, or Subject Matter Experts, were invited to join sessions and work collaboratively with students as content contributors and content creators. Students logged-out of these online sessions knowing 'what', but also knowing 'how' and 'where'. For example, the students selected the topic 'The Great Barrier Reef' and accessed websites to find information on coral bleaching and the wreck of the 'Pandora'. The students participated in a question and answer session via teleconference with a world renowned expert on marine ecology who was one of the team that discovered the 'Pandora' wreck (Figure 4). 


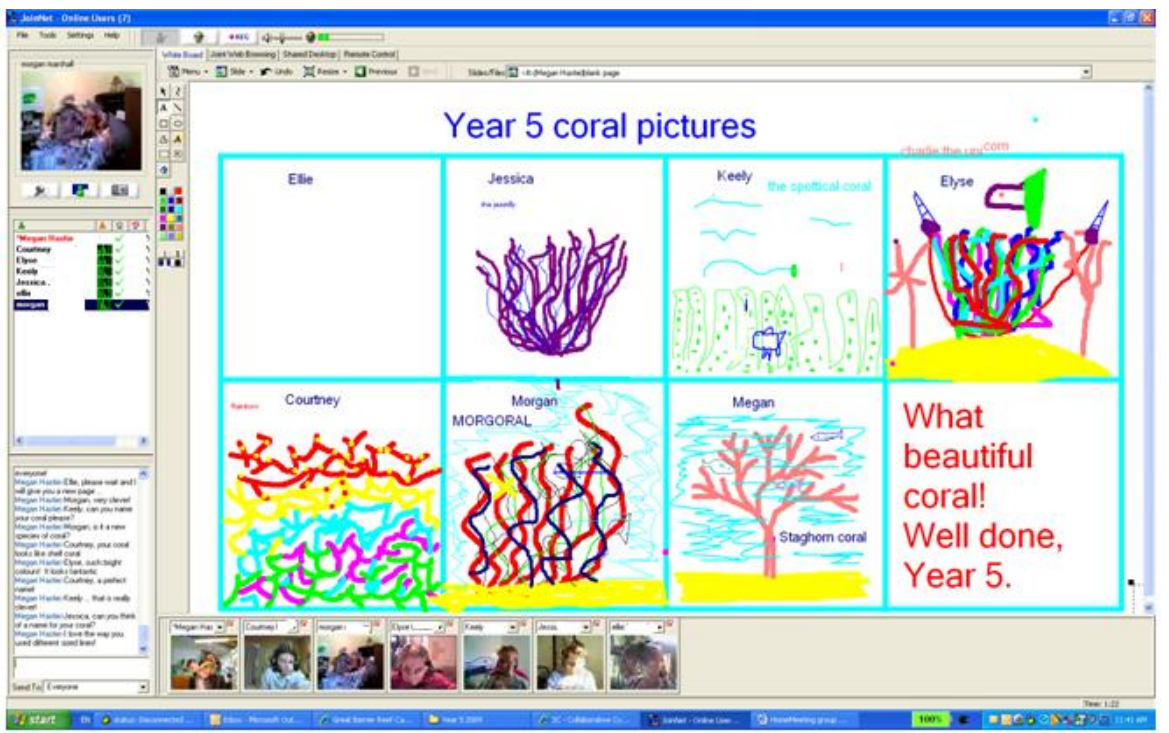

Figure 4. Year 5 students creating content about coral species in the $3 \mathrm{C}$ synchronous cyber classroom

The students in Case Study 1 were voluntary participants and their interaction and collaboration throughout the trial was enthusiastic, innovative, creative and joyous. Attendance was consistently high and students rarely missed sessions. When asked how they felt about being involved in decision-making around content they said they felt "really important" and "good" and "more interested. Feedback from the parents of the students confirmed the high levels of interest, motivation and enjoyment demonstrated by the students when they were actively involved in the decision-making around content. Case Study 1 points to enhanced learning outcomes for students aged 5 to 10 years when a range of age-appropriate strategies are used to negotiate content in a technology enhanced teaching and learning environment.

Case Study 2 reports on a new collaboration that commenced in 2009 between the Hear and Say Centre (Hear and Say), Brisbane, Australia, Brisbane School of Distance Education (BSDE), Australia, and the National Sun Yat-Sen University (NSYSU), Taiwan. The collaboration has focussed on the development of content for the Hear and Say WorldWide global professional training courses in hearing health and AuditoryVerbal Therapy (A-VT). The courses were developed for adult learners living in Queensland and other Australian states and territories, and for wider global distribution, with a specific focus on developing nations. A 'Blended Cyber' mode of delivery was developed using 3C (Hastie, Hung, Chen, \& Kinshuk, 2010).

With hearing loss being the most common disability in newborn babies throughout the world, and with the advent of the cochlear implant technology, Dimity Dornan, Founder and Managing Director of the Hear and Say Centre, recognised the need to develop global training courses to train more hearing health professionals worldwide to teach children with hearing impairment. This will enable children with hearing loss to learn to listen and speak, and to develop speech, language, vocabulary and listening outcomes commensurate with their hearing peers. This approach teaches the children's parents how to use the A-VT techniques at home to reinforce and expedite their children's listening and speaking skill development (Dornan et al., 2009). Prior to the collaboration with NSYSU, the Hear and Say courses had been conducted in Australia 
and in 11 countries overseas in Physical Face-to-Face mode. The exponential growth in the number of children with hearing impairment globally has highlighted the urgent need to train greater numbers of hearing health workers in the specialty area of A-VT, and is now a priority for Hear and Say WorldWide. The e-learning adaptation of the traditional F2F Hear and Say courses, using technology enhanced teaching and learning, is critical to meeting the training needs of hearing health workers in rural and remote locations in Australia, and in developing nations in the Asia-Pacific region and beyond.

In 2010 the Hear and Say WorldWide e-learning project received funding from Education Queensland for the development of two courses and for the salary of one teacher. Ms Megan Hastie (BSDE) was employed as a Project Officer to facilitate the collaboration between Education Queensland and Hear and Say, and to act as a 'critical friend' in the development of the Hear and Say Worldwide e-learning courses.

The asynchronous and synchronous features of 3C platform, supported by the National Sun Yat-Sen University, were used to store and develop Hear and Say course content for the e-learning adaptation the existing PF2F courses. The priority in early 2010 was the development of the Hear and Say WorldWide e-learning Intermediate Course for launch in July, 2010.

The original Hear and Say Intermediate Course had been developed over a seven year period and consisted of twenty-three Physical Face-to-Face (PF2F) lectures. The lectures had been written by the Hear and Say Clinical Team - acknowledged world leaders in A-VT and hearing health. The content for the PF2F course had previously been delivered in a one-week intensive program using a combination of PowerPoint presentations, live and recorded demonstrations and interactive discussion. The course content included the hearing system, Audiological assessment, and the management of hearing loss, and A-VT techniques and practical applications to help professionals apply A-VT in their own workplaces. A Blended Cyber mode of delivery was adopted to ensure 'flexible' delivery that will provide a wide range of situation specific options, especially in rural and remote locations and developing nations.

Changes to content and design were negotiated with the Clinical Team and the Hear and Say Management Team in a process of ongoing consultation and collaboration. The original PF2F courses had been developed by the Clinical Team and reflected their clinical expertise as Audiologists and Speech Pathologists. Few had formal background in teacher training but were 'intuitively' highly effective teachers. As a consequence the lectures that comprised the original course were written as a 'narrative' and reflected the style of individual writers.

The decision-making around content was based on Hear and Say's prior experience and knowledge of the needs for health workers undertaking A-VT training in their PF2F courses. The decision-making process was also driven by the academic requirements for tertiary accreditation of the Hear and Say courses by the University of Southern Queensland. The content for the original twenty-three PowerPoint lectures that comprised the traditional PF2F Intermediate Course was reviewed.

The Course was structured to include the original lectures which were renamed 'Topics' and grouped under four 'Unit' headings. 'Objectives' were written for each Topic and designed to explicitly inform the participants of the teaching and learning expectations from the outset. The 'Objectives' were followed by a 'Reflection' exercise to stimulate recall of prior learning. The content for each Topic was written to match the 'Objectives' and followed the 'Reflection'. The content was designed to teach new knowledge and skills as stated in the Objectives. A series of 'Tasks' were written for each 
Topic. These were interspersed throughout the content at strategic points, requiring the course participants to interact with the content and practice the new knowledge and skills. At the end of the Topic a 'Summary' of the expected learning outcomes was explicitly stated to check retention and assist participants in the transfer of their new knowledge and skills to their role as Auditory-Verbal Therapy practitioners.

In mid-June 2010, the Hear and Say WorldWide e-learning Intermediate Course was uploaded to the $3 \mathrm{C}$ platform, as shown in Figure 5.

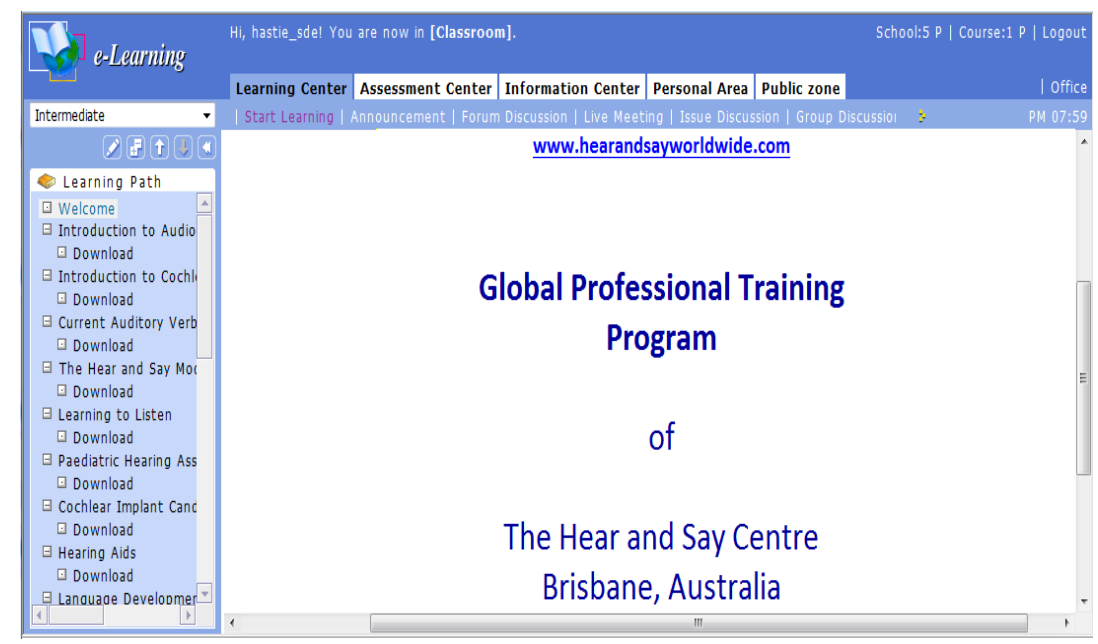

Figure 5. A screen-capture showing asynchronous content on the $3 \mathrm{C}$ platform for the Hear and Say WorldWide Intermediate Course

These materials formed the new asynchronous component of the course. An instructional design model (Gagne) was used to provide a pedagogically sound format for the course, as shown in Table 2.

Table 2. Gagne's Nine Instructional Events applied to the Hear and Say WorldWide e-Learning Courses

\begin{tabular}{|l|l|}
\hline $\begin{array}{l}\text { GAGNE'S INSTRUCTIONAL } \\
\text { EVENTS }\end{array}$ & $\begin{array}{l}\text { APPLIED TO THE HEAR AND SAY WORLDWIDE } \\
\text { COURSES }\end{array}$ \\
\hline 1. Gain attention & Welcome participants and introduce the Topic \\
\hline 2. Inform learners of objectives & Objectives stated explicitly at the start as an advance organizer \\
\hline 3. Stimulate recall of prior learning & Reflection exercise: 'What do you already know about ...' \\
\hline 4. Present the content & $\begin{array}{l}\text { Auditory-Verbal philosophy and practice } \\
\text { Focus on participant 'interactivity' }\end{array}$ \\
\hline 5. Provide 'learning guidance' & $\begin{array}{l}\text { Practical knowledge, skills and strategies } \\
\text { Use print, digital and multi-media resources }\end{array}$ \\
\hline 6. Elicit performance (practice) & $\begin{array}{l}\text { Individual and group discussion } \\
\text { Practicum }\end{array}$ \\
\hline 7. Provide feedback & $\begin{array}{l}\text { Teacher-Participant and Participant- Participant } \\
\text { Verbal, written }\end{array}$ \\
\hline 8. Assess performance & $\begin{array}{l}\text { Observation and interaction during Course } \\
\text { Multiple choice examination at end of Course }\end{array}$ \\
\hline 9. Enhance retention and transfer to the job & $\begin{array}{l}\text { Knowledge and skills applied to real-life role as an Auditory-Verbal } \\
\text { practitioner }\end{array}$ \\
\hline
\end{tabular}


Participants were issued with personal Usernames and Passwords by the Platform Administrator which enabled them to access the course materials at anytime and from anywhere. Recorded voice-overs were added to some Topics to allow participants to listen to specific course content that could be best communicated verbally. A Course Profile, Teacher Guides and Student Workbooks were developed to complement the asynchronous resources. The synchronous cyber features of the $3 \mathrm{C}$ platform will be used by participants and the Clinical Staff to engage in interactive collaborative teaching and learning during the inaugural Hear and Say e-learning Intermediate Course in July 2010. Further research findings emerged from this trial and resulted in a significant revision of content and the uploading of a new version of the Intermediate Course content to 3C. The e-Learning Project Team negotiated the content revisions with the Clinical Staff, who were the course instructors, and the Hear and Say Management Team. The revised content for the Intermediate Course was then uploaded to the 3C platform. The new version of Intermediate combined the information on the original PowerPoint presentations and the teaching notes, plus links to URLs and multi-media resources. The design features used in the revised Intermediate Course were subsequently applied to the Advanced Course and became a template for all courses.

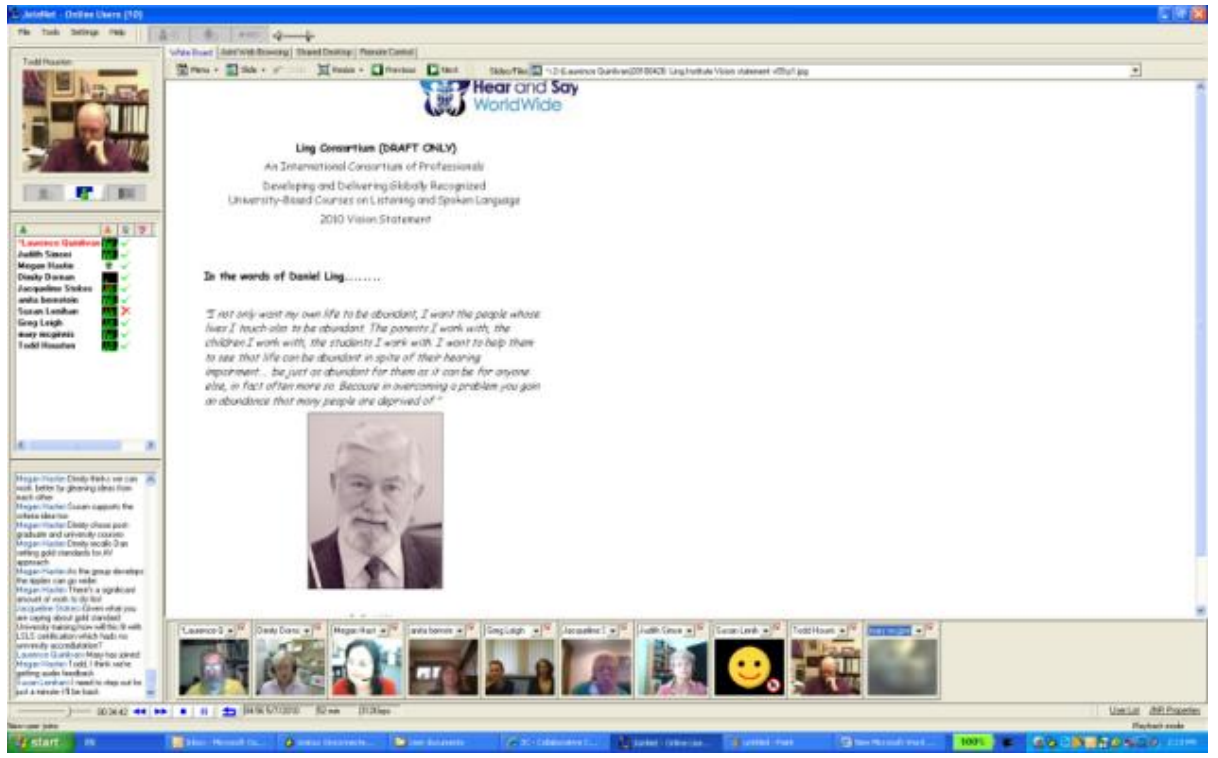

Figure 6. A screen-capture showing an international collaboration in CF2F mode via the 3C platform between world experts in Auditory-Verbal Therapy to develop global A-VT content standards

A trial of the second Hear and Say WorldWide e-learning Course, the Advanced, was undertaken in December 2010. The Advanced Course used a Blended Cyber mode of delivery in which technology enhanced learning was the negotiating tool for decisionmaking around content. All participants (100\%) rated the design of the asynchronous course content as highly learner-friendly and gave a medium-high rating to its quality and relevance. All participants $(100 \%)$ stated that they would recommend the Hear and Say eLearning course to others. The majority of Instructors $(60 \%)$ stated that they were 'Comfortable' participating in cyber synchronous sessions on the $3 \mathrm{C}$ platform using a Blended Cyber mode for content delivery. The use of the synchronous face-to-face features of the $3 \mathrm{C}$ platform by Dimity Dornan, Hear and Say Centre, Brisbane, for 
collaborative international development of Auditory-Verbal Therapy standards is shown in Figure 6.

\section{Findings and Discussion}

In this paper we report on a new approach that we have applied in two educational settings using technology enhanced teaching solutions as the negotiating 'tool' in content development decision-making. The major finding in our study is that content is changing - and if it is not changing, it needs to. We summarise this finding in Table 3 below through a comparison between Traditional Content and Negotiated Content:

Table 3. Traditional Content vs. Negotiated Content

\begin{tabular}{|c|c|}
\hline Traditional content & Negotiated content \\
\hline Based on knowledge 'traditions' & Basis of a new media age \\
\hline Institution centric & Situation and learner specific \\
\hline Focus is on mastery of content & $\begin{array}{l}\text { Focus is on new ways of learning using new } \\
\text { technology enhanced learning tools and new thinking } \\
\text { power }\end{array}$ \\
\hline Learning is formal & Learning is informal \\
\hline Setting is usually Physical Face-to-Face (PF2F) & $\begin{array}{l}\text { Setting can be Physical Face-to-Face (PF2F) or } \\
\text { Blended Cyber (BC) or Cyber Face-to-Face (CF2F) }\end{array}$ \\
\hline Instructor provides content & $\begin{array}{l}\text { Teams of learners and learning managers and subject } \\
\text { matter experts create content }\end{array}$ \\
\hline $\begin{array}{l}\text { Instructor imparts 'knowledge' in print and/or via } \\
\text { PF2F lecture (message delivery) }\end{array}$ & $\begin{array}{l}\text { Learning managers facilitate learner participation in } \\
\text { e-learning content development (conversation) in BC } \\
\text { or CF2F environments }\end{array}$ \\
\hline Emphasis is on passive decoding & Emphasis is on interactivity and encoding \\
\hline $\begin{array}{l}\text { Learners join a school or academic community to } \\
\text { access prescribed content }\end{array}$ & $\begin{array}{l}\text { Learners 'surf' virtual learning 'spaces' that are nodes } \\
\text { on the network, anywhere and anytime, to access and } \\
\text { create unlimited content }\end{array}$ \\
\hline Learners exit knowing 'what' & Learners exit knowing 'what', 'how' and 'where' \\
\hline
\end{tabular}

Our interpretation of the 'quantum shift' from traditional content paradigms to a negotiated content approach, as summarised in Table 1, is supported by the literature (Prensky, 2000; Fanton, 2009). It is apparent that the new digital technologies and the increasing demands of digital learners, their learning managers and subject matter experts are the driving force behind changes in content. They want to do things differently and they have the 'tools' to do it.

We were able to identify digitally-driven changes in decisions around content development in both case studies: First, the two studies used a negotiated content approach to respond to the demands of different groups of learners, learning managers and subject matter experts. Both studies demonstrate how theory can be put into practice and how digital technologies can be used to shape and create a new type of content and thus, a new way of thinking and learning.

Second, the two studies recognised the economic, social and technology trends that have driven the digital age in first world countries and as a consequence provide models that can be applied in developing nations for projects such as those envisaged by Hear and Say Worldwide. Both studies sought to realise the full interactive potential of digital technologies using a 'Blended Cyber' model to overcome the complex situation specific challenges for learners in rural and remote communities and in developing 
nations. In particular, the negotiation process ensured that content was rigorously 'vetted' for relevance and thus would help build capacity. This bodes well for future international collaborations between educational and specialty health training organizations, such as Education Queensland and Hear and Say Worldwide, using technology enhanced teaching and learning in sites throughout Australia and the AsiaPacific region.

Third, the two studies suggest that there are lessons to learn from very young digital learners who are outstripping our expectations in terms of breadth and depth of learning when engaged in a negotiated content approach. It is a sad indictment on most traditional educational environments that learners become conditioned from the start of their formal education to be 'consumers' of content rather than creators, and teachers become 'providers' rather than facilitators. In an age where we are beset with a myriad of problems and learners are increasingly being expected to apply a 'problem solving' approach, it is time to stop telling them 'what' to learn and allow them to use every tool at their disposal, specifically the Web 2.0 tools, to identify the problems, work out how to solve them and where to find the resources they need to do so. This is liberating not only for learners but also for teachers who can move from being mere 'megaphones' in the traditional top-down content delivery mode to co-creators of content and learning managers in the Digital Age. When asked to reflect on the negotiated content approach used in their online lessons, students as young as five years of age stated that they felt "really important" and "good" and "more interested" when they were actively involved in the decision-making around content. Surely we want young learners, and all learners, to feel this way? If students can be trained to use Web 2.0 tools to negotiate content from five years of age, as this paper so clearly demonstrates, it is clear that this approach can be successfully applied across the full spectrum of learning - from early childhood to tertiary.

Finally, the lead author of this paper points out that the development of this new approach to content was not without risk and has at times been met with scepticism by some colleagues. It is not easy to challenge the custodians of 'traditional' content and traditional ways of 'knowing' and 'doing'. The proving point throughout this study, however, has been the extra-ordinary outcomes demonstrated by the learners themselves. In particular, the enthusiasm and creativity with which digital learners used digital tools to plan and create their own learning content in collaborative learning environments, and the privilege of witnessing their empowerment throughout this process, is the lasting legacy of this study. Research on a 'negotiated content' approach using technology enhanced learning solutions in educational and health settings in Australia and the AsiaPacific region is being undertaken through ongoing collaborations between BSDE, Hear and Say and NSYSU.

\section{Conclusion}

In this paper we describe how we engaged in conversations with learners and instructors and asked them what they want and need to learn, rather than presuming what and how they should learn. If we are to optimise the full potential of the new digital tools it is imperative that we encourage 'Net Gen' to show us what they can do with them. Digital learners want to use the new digital tools to create new ways of thinking and learning in conversations with their peers, their learning managers and with subject matter experts. In this way, the traditional forms of e-reading and e-listening resources that package traditional content in learning management systems can be superseded, thus reducing the 
risk of redundancy. This is what digital learners want and need to meet the challenges of a changing world. In short, the digital tools that today's digital learners manipulate so effortlessly fulfil the promise of them having a say in what they are learning. The tools empower them to negotiate with teachers and to become content contributors, an outcome beyond just knowing what or how. Our work points to opportunities that will shape our thinkers, now and in the future.

\section{Acknowledgements}

This research was supported by the National Science Council, Taiwan under project numbers NSC97-2511-S-110-005-MY3, NSC99-2631-S-011-002 and NSC99-2511-S110-004-MY3.

\section{References}

1. Ala-Mutka, K., Bacigalupo, M., Kluzer, S., Pascu, C., Punie, Y. \& Redecker, C. (2009). Learning2.0: The Impact of Web2.0 Innovation on Education and Training in Europe. Obtained through the Internet. Available at: ftp://ftp.jrc.es/pub/EURdoc/JRC50704.pdf.

2. Chen, N.S., Kinshuk, Wei, C.W., \& Liu, C.C. (2011). Effects of matching teaching strategy to thinking style on learner's quality of reflection in an online learning environment. Computers \& Education, 56(1), 53-64.

3. Chen, N.S., Ko, H.C., Kinshuk, \& Lin, T. (2005). A model for synchronous learning using the Internet. Innovations in Education and Teaching International, 42 (2), 181-194.

4. Chen, N.S., \& Ko, L. (2010). An Online Synchronous Test for Professional Interpreters. Educational Technology \& Society, 13(2), 153-165.

5. Chen, N.S., Wei, C.W., Wu, K.T., \& Uden, L. (2009). Effects of high level prompts and peer assessment on online learners' reflection levels. Computers \& Education, 52(2), 283-291.

6. Dornan, D., Hickson, L., Murdoch, B., Houston, T. (2009). Longitudinal Study of Speech Perception, Speech, and Language for Children with Hearing Loss in an Auditory-Verbal Therapy Program. The Volta Review, 109(Fall/Winter), 61-85.

7. Fanton, J. (2009). What Wikipedia Can Teach Us About The New Media Literacies. Obtained through the Internet. Available at: http://www.journalofmedialiteracy.org/index.php/past-issues/3-the-new-literacyrenaissance-v54-n2a3/157-what-wikipedia-can-teach-us-about-the-new-medialiteracies.

8. Hastie, M., Chen, N.S. \& Kuo, Y.H. (2007). Instructional Design for Best Practice in the Synchronous Cyber Classroom. Educational Technology \& Society, 10(4), 281-294.

9. Hastie, M., Hung, I.C., Chen, N.S. \& Kinshuk. (2010). A Blended Synchronous Learning Model for Educational International Collaborations. Innovations in Education and Teaching International, 47(1), 9-24.

10. Hastie, M. \& Chen, N.S. (2006). Working brain-to-brain: Real learning - Teacherdirected Online Live Lessons Using a Synchronous Cyber Classroom. The Australian Computers in Education Conference 2006 (ACEC 2006) 2-4, Oct. Cairns, Queensland. 
11. Hastie, M., Chen, N.S. \& Leeming, D (2009). Using Technology Enhanced Learning Solutions to Build Bridges across the Digital Divide Towards 'empowerment' in Australia and the Asia-Pacific Region, The Technology Enhanced Learning conference (TELearn2009), Taiwan.

12. Hastie, M., Chen, N.S. \& Todd, R.J. (2008). Multiple participants, multiple locations, multiple time zones and multitasking in the synchronous cyber classroom. The 8th IEEE International Conference on Advanced Learning Technologies (ICALT-2008), July 1-5, Santander, Spain. IEEE Computer Society Press, pp. 654-656.

13. Hastie, M., \& Chen, N.S. (2008). Collaborate or Perish: Educational Imperatives for International Collaboration in the anywhere, anytime digital marketplace. The Technology Enhanced Learning Conference 2008 (TELearn2008), Vietnam.

14. Levy, M., Wang, Y., \& Chen, N.S. (2009). Developing the skills and techniques for online language teaching: A focus on the process. Innovation in Language Learning and Teaching, 3(1), 16-33.

15. Musser, J., \& O'Reilly, T. (2006). Web 2.0 Principles and Best Practices. Obtained through the Internet. Available at: http://oreilly.com/catalog/web2report/chapter/web20_report_excerpt.pdf.

16. Nowotny, H., Scott, P., \& Gibbons, M. (2003). 'Mode 2' Revisited: The New Production of Knowledge. Minerva, 41, 186.

17. Prensky, M. (2001). Digital Natives, Digital Immigrants. On the Horizon, 9(5) (October 2001). Obtained through the Internet. Available at: http://www.marcprensky.com/writing/.

18. Samuel, A. (2007). Best Practices for Non-profits Using Web 2.0. Obtained through the Internet. Available at: http://www.socialsignal.com/blog/alexandrasamuel/best-practices-for-non-profits-using-web-2-0.

19. Siemens, G. (2004). Connectivism: A Learning Theory for the Digital Age. elearnspace, December 12, 2004. Obtained through the Internet. Available at: http://www.elearnspace.org/Articles/connectivism.htm.

20. Wang, Y., \& Chen, N.S. (2009). Criteria for evaluating synchronous learning management systems: Arguments from the distance language classroom. Computer Assisted Language Learning, 22(1), 1-18

21. Wang, Y., Chen, N.S., \& Levy, M. (2010a). The design and implementation of a holistic training model for language teacher education in a cyber face-to-face learning environment. Computers and Education, 55(2), 777-788.

22. Wang, Y., Chen, N.S., \& Levy, M. (2010b). Teacher training in a synchronous cyber face-to-face classroom: Characterizing and supporting the online teachers' learning process. Computer Assisted Language Learning, 23(4), 277-293. 